\title{
EL IMAGINARIO SOBRE LA MIGRACIÓN INTERNACIONAL: EL DESEO DE TRABAJAR EN ESTADOS UNIDOS EN JEFES DE HOGAR DEL SEXO MASCULINO EN LA ZONA METROPOLITANA DE MONTERREY. UNA APROXIMACIÓN INDIRECTA
}

\author{
Por \\ Victor Zuninga* \\ RESUMEN
}

\begin{abstract}
El presente trabajo describe y analiza respuestas de jefes de hogar (y/o de sus cónyuges) de la zona metropolitana de Monterrey en tomo a la pregunta: ¿le gustaría trabajar en Estados Unidos? Se intenta, de esta manera, contribuir al estudio de la inagen que tenemos los mexicanos sobre Estados Unidos y desmentir algunas percepciones estadounidenses en tomo a la migración internacional de México a la Unión Americana.
\end{abstract}

\begin{abstract}
This work describes and analyzes the different responses to the question: Would you like to work in the United States? This question was asked to the head of the households in Monterrey (Mexico). The purpose of this work is to have an approximation about the image that Mexicans have about the United States as well as to give the lie to some perceptions of the U.S. people about the Mexican migration to that country.
\end{abstract}

\section{INTRODUCCIÓN}

i) En la seric de trabajos preparados para la Comisión sobre el Futuro de las Relaciones México-Estados Unidos, se incluyó, como primer volumen, un conjunto de documentos intitulados "Imágenes de México en Estados Unidos" (Coatsworth y Rico, 1989) en el que se analizan y discuten las creencias e imágenes (el imaginario) de los estadounidenses sobre México expresados a través del cine, los libros de texto escolares, los diarios y la opinión del público sobre las relaciones entre ambos países.

Ciertamente cl título mismo y la introducción de los coordinadores del volumen hablan de la paradójica ausencia de trabajos en los que se describan y analicen las imágenes que los mexicanos tienen sobre Estados

- Investigador de El Colegio de la Frontera Norte. Oficina Coordinadora de Monterrey. 
Unidos: "La falta de estudios que analicen las percepciones mexicanas acerca de Estados Unidos es, por tanto, mucho más sorprendente de lo que sería si este país no fuera una realidad tan inevitable de la cultura política y la vida cotidiana de los mexicanos" (Coatsworth y Rico, 1989:24).

Los autores dan a conocer la existencia de encuestas realizadas a fines de los años ochenta cuyo objetivo es precisamente conocer las percepciones que los mexicanos tienen del país vecino. Sin embargo, sorprende nuevamente que estas encuestas fueran realizadas por especialistas norteamericanos a solicitud de agencias de su país: New York Times, Clancy Shulman Associates. Todo indicaría que la preocupación sobre la imagen de Estados Unidos en México es una preocupación de Estados Unidos y que, en gran medida, la preocupación sobre la imagen de México en Estados Unidos, también es una preocupación norteamericana.

La importancia del estudio de los imaginarios es sin duda de orden político:

El comportamiento de los actores internacionales está condicionado por los filtros culturales a través de los cuales éstos reciben e interpretan información acerca de otros actores. Así es como las imágenes culturalmente condicionadas y los estereotipos ejercen un efecto poderoso sobre la toma de decisiones... la acción estatal puede estar constreñida, en mayor omenor grado, por las imágenes dominantes que existen en una sociedad (Coatsworth y Rico, 1989:15-16). ${ }^{2}$

Pero también presenta una importancia económica; el flujo de intercambios técnicos entre México y Estados Unidos es inherentemente a un intercambio cultural vía asesorías, cursos de entrenamiento y capacitación, esquemas diversos de subcontratación, consultorías, etcétera. Intercambio irremediablemente mediado por imaginarios, es decir, estereotipos, reputaciones, imputaciones, creencias, prejuicios. ${ }^{3}$

ii) Una de las posibles imágenes estadounidenses sobre México tiene relación con la llamada "invasión silenciosa" o "invasión cafe"; trasfondo cultural de las medidas de control migratorio y matriz de las concepciones y expresiones utilizadas para designar la migración indocumentada. Como lo observa J. Bustamante (1990:6):

1 Una excepción puede encontrarse en el trabajo de Francisco J. Moreno (1992).

2 La reciente discusión pública en México sobre el contenido de los nuevos libros de texto gratuitos de historia para la escuela primaria, es una muestra de la importancia política de la sensibilidad social a las imágenes que se tienen del país vecino, especificamente las que se yan a transmitir oficialmente a los nifios.

3 La literatura sobre el tema es inexistente, salvo algunas referencias de Pablo Villa (1992). 
In the US (la migración mexicana) is viewed basically as crimerelated therefore requiring domestic solutions (under US legislation) of a police nature. Migrants are commonly called "illegal alliens" and are generally viewed negatively, as a threat, a sort of disease or plague caused by factors outside the US, of which the US is a victim. ${ }^{4}$

En concordancia con estos elementos del imaginario estadounidense, se piensa que si desaparecieran las barreras legales para emigrar desde México hacia Estados Unidos, la república mexicana se vaciaría. Es decir, una gran mayoría de los habitantes del país optarían por trasladar su domicilio a la Unión Americana y buscar empleo en ese país. Esta bien pudiera ser una creencia más difundida entre los estadounidenses blancos y México-norteamericanos de lo que en el presente trabajo se supone.

Si bien esta creencia no es más que un eslabón del complejo y poco estudiado edificio imaginario que los ciudadanos estadounidenses se forjan sobre su vecino del sur, tiene consecuencias importantes en la toma de decisiones: crea un consenso a favor del endurecimiento de las medidas de control migratorio en la frontera México-norteamericana.

De hecho, en las encuestas de opinión analizadas por Christine E. Contee (1989) sobresale el hecho de que la gran mayoría del público norteamericano apoya la idea de que "Estados Unidos debe de limitar el número de inmigrantes que entran al país". Y más de un tercio de los encuestados considera que la inmigración indocumentada es el asunto que más afecta las relaciones bilaterales entre México y Estados Unidos.

iii) El presente artículo ofrece una modesta contribución a dos de las preocupaciones arriba planteadas: $a$ ) la carencia de estudios sobre la imagen que los mexicanos tienen sobre los Estados Unidos y, $b$ ) la idea dominante que los estadounidenses parecen tener de la migración internacional desde México.

Con estos propósitos, en primer lugar se describirán y clasificarán las respuestas de habitantes de la zona metropolitana de Monterrey en torno a la pregunta: ¿Le gustaría alguna vez trabajar en Estados Unidos? Y, en segundo lugar, se caracterizarán los jefes de hogar residentes en la zona metropolitana de Monterrey que manifiestan su rechazo a la idea de trabajar en Estados Unidos.

\footnotetext{
4 N. del E."En los Estados Unidos (la migración mexicana) básicamente es vista como relacionada con el crimen, y que por tanto requiere soluciones domésticas (en la legislación norteamericana) la naturaleza policiaca a los migrantes comúnmente se les denomina 'extranjeros ilegales' y por lo general son vistos negativamente, como una amenaza, una especie de enfermedad oplaga causada por factores extemos a los Estados Unidos, de los que Estados Unidos es una víctima".
} 


\section{LIMITACIONES METODOLÓGICAS}

i) Los datos utilizados en el presente trabajo fueron tomados de una encuesta de hogares realizada sobre una muestra representativa de 488 viviendas del municipio de Guadalupe, N.L., segundo en importancia poblacional dentro de la zona metropolitana de Monterrey $(\mathrm{ZMM}){ }^{5} \mathrm{La}$ parte más importante del trabajo de campo se realizó durante los últimos meses de 1991.

La encuesta, ${ }^{6}$ que dirige principalmente su atención a los jefes de hogar del sexo masculino, buscaba cumplir tres objetivos: $a$ ) medir la importancia de la emigración internacional dentro de la trayectoria laboral de los trabajadores de laZMM; $b$ ) comparar un municipio de la zona metropolitana de Monterrey con otras ciudades del país; $c$ ) definir algunas características del proceso migratorio internacional que se gesta en las principales ciudades del país.

ii) De la encuesta surge la siguiente distribución de los jefes de hogar: 82 habían trabajado, al menos una vez, en Estados Unidos y 406 no tenían ninguna experiencia laboral extrafronteras. $\mathrm{Al}$ interior de este segundo grupo, se produce una segunda distribución: 120 manifestaron que desearían trabajar en Estados Unidos, 269 indicaron que no desean laborar en ese país y los restantes 17 jefes de hogar no respondieron.

La entrevista interrogaba al informante sobre el deseo de trabajar en Estados Unidos y en función de su respuesta se solicitaba una explicación adicional. Si el informante afirmaba que sí deseaba trabajar en Estados Unidos, el encuestador continuaba con la pregunta: ¿Y por qué no lo ha hecho?; en caso contrario, se le invitaba a explicar los motivos por los cuales no deseaba trabajar en Estados Unidos.

Como se observará, el procedimiento presenta dos grandes desventajas:

- Por un lado, los objetivos, diseño y procedimientos de la encuesta no permiten abordar con detalle los numerosos ingredientes simbólicos

5 La zona metropolitana de Monterrey actualmente está compuesta por nueve municipios conurbados: Apodaca, Escobedo, García, Guadalupe, Juárez, Monterrey, San Pedro, Santa Catarina y San Nicolás de los Garza. En este contexto urbano, Guadalupe ha cumplido, desde los años cuarenta, cuatro funciones esenciales: ciudad dormitorio, receptáculo de migrantes de origen rural, reserva electoral para el partido político dominante y asiento de pequeñas unidades productivas o de servicios que dan empleo a una porción relativamente importante de la PBA municipal. Durante las décadas de los sesenta y setenta es el municipio que crece a ritmos más rápidos: a tasas medias anuales de crecimiento intercensal de $16.01 \%$ entre 1960 y 1970 , y de $8.47 \%$ en la siguiente década, alcanzando una población de 535,560 habitantes ên el último censo (Pozas, 1990; Zúñiga, 1990).

La encuesta "Emigración internacional desde la zona metropolitana de Monterrey: COLRP/AMBP 1991" fue financiada por la Asociación Mexicana de Población. 
que van incluidos en una explicación sobre situaciones imaginarias ("¿le gustaría a Ud. trabajar en Estados Unidos?", en caso afirmativo: "¿por qué no lo ha hecho?"; en caso negativo: "¿por qué no le gustaría trabajar en ese país?"); el tipo de entrevista (numerosas preguntas, poco tiempo para establecer diálogos entre el entrevistado y el entrevistador) dificulta recoger relatos o discursos de los interlocutores. En pocas palabras, la encuesta provee información relevante pero poco profunda sobre las imágenes y creencias de los encuestados.

- Por otro lado, la entrevista fue dirigida generalmente (78\% de los casos) al ama de casa, cónyuge del jefe del hogar. De suerte que las respuestas y las explicaciones constituyen las explicaciones femeninas y domésticas de la aceptación o rechazo del jefe de hogar a la migración internacional. Esto, si bien no resta validez a los datos (es aceptable creer que la cónyuge conoce las intenciones migratorias de su pareja), sí modifica de manera importante la interpretación de los mismos.

\section{CLASIFICACIÓN DE LAS RESPUESTAS}

i) Como se anotó anteriormente, y en función de nuestros propósitos, la muestra puede dividirse en tres grandes grupos: el de los migrantes internacionales (17\%), el de los no migrantes internacionales que desearían trabajar en Estados Unidos (25\%) y el de los no migrantes internacionales que no desean trabajar en Estados Unidos (55\%).

Interesa, en primer término, transcribir y clasificar las respuestas del grupo más numeroso: el de los jefes de hogar que no poseen experiencia laboral extrafronteras y que no desean tenerla.

\section{¿Por qué no desean trabajar en Estados Unidos?}

1. Porque, desde el punto de vista laboral, México y Estados Unidos ofrecen lo mismo; no existen diferencias sustanciales en ambos mercados de trabajo o las diferencias existentes no ameritan una decisión tan riesgosa y compleja como la de emigrar al vecino país:

- "No, porque en México hay muchas fuentes de trabajo" (electricista desempleado, 35 años).

- "No, porque aquí hay en que trabajar" (comerciante ambulante, 54 años).

7 El restante 3\% corresponde a los que no respondieron. 
- "Aquí estamos bien, para qué irse" (ayudante de albañil, 45 años).

- "No, es lo mismo" (obrero de Vidriera Monterrey, 39 años).

- "No, porque aquí hay mucho trabajo" (pensionado después de haber trabajado en una fábrica de alfarerías, 62 años).

- "Dice que no le gusta, dice que aquí trabaja bien, se enoja porque oye que se van, es igual aquí que allă" (albañil, 48 años).

- "Aquí mejor, lo que puedo ganar allá lo puedo ganar aqui" (albañil, 31 años).

2. Porque el mercado laboral norteamericano ofrece solamente migajas; no es un mercado abierto a la mano de obra mexicana salvo en los puestos de trabajo menos pagados y menos apreciados socialmente; no es un mercado de trabajo que ofrezca expectativas favorables a los mexicanos que deciden integrarse a él:

- "No, porque oye las noticias del maltrato y de que no hay buenos trabajos" (vigilante en un supermercado, 26 años).

- "Aquí tengo mi trabajo, por eso no me voy aunque tengo mi familia allá, mi papá y mis hermanos están en Dallas" (empleado del departamento de mantenimiento del IMSS, 32 años).

- "Allá los mexicanos no progresan" (chofer de grúas y maquinaria pesada, 50 años).

- "No le llama la atención trabajar allá; sí ir a pasear, pero trabajar 'no' ya que está establecido aquí" (comerciante propietario de una ferretería, 60 años).

- "No, porque tiene un hermano allá y nunca ha hecho nada" (agente de ventas de Cervecería Cuauhtémoc, 36 años).

- "Si no hace uno nada aquí, menos alla" (obrero en una industria, 42 años).

- "Allá no voy a poder desarrollar mi profesión" (contador público, 31 años).

3. En ocasiones, la explicación se ensancha para subrayar la forma como los mexicanos son tratados, recibidos por la sociedad norteamericana. No son bienvenidos, todo lo contrario, el maltrato es una constante:

- "No, porque una vez lo quise hacer y no me quedaron ganas" (técnico en climas, 40 años).

- "No me voy por mi familia y porque tengo miedo por eso de los desaparecidos" (chofer de vehículos de transporte, 46 años). 
- "No, es mucho riesgo" (obrero de fábrica procesadora de alimentos, 36 años).

- "No, por lo que le dicen de cómo les va a los que se van allá" (empleado del IMSS, 36 años).

- "No, no va a tener uno derechos como en su país" (repartidor de botanas, 36 años).

- "No porque ellos nos han venido a robar cosas y además es muy arriesgado para los mexicanos" (jubilado de TELMEX, 51 años).

- "No, porque utilizan sangre ajena en sus guerras y por eso no me voy" (auxiliar administrativo, 36 años).

4. Especialmente relevante es el hecho de que numerosas explicaciones se sitúan en el terreno de la evaluación cultural de Estados Unidos. Los entrevistados aducen al estilo de vida estadounidense en sí mismo y afirman que no es apreciable. La sociedad norteamericana no ofrece a sus habitantes un entorno humano deseable. No es el trato a los mexicanos en especial lo que preocupa, sino las características socioculturales de Estados Unidos:

- "No, porque no le convence el sistema de vida" (jefe de turno, 36 años).

- "No le gusta la vida de Estados Unidos" (dueño de camiones de volteo, 62 años).

- "No le gusta la vida de allá" (delegado sindical del IMSS, 38 años).

- "No le gusta ese país para vivir" (profesor de primaria, 34 años).

- "No le gusta, su país es México, no le gustaría vivir en otro país" (albañil, 51 años).

- "No, porque la música de aquí para él es su felicidad" (músico, 70 años).

- "No le gusta Estados Unidos" (agente de tránsito, 49 años).

- "No, porque aquí me siento a gusto, y a mi esposa no le gusta el otro lado" (empleado de una fábrica, 37 años).

- "No le gusta la vida de Estados Unidos" (empleado de empresa de alfombras, 36 años).

- "No me agrada ir allá, no tengo nada qué conocer allá" (gerente de área de cadena de farmacias de Monterrey, 35 años).

- "No le convence el ambiente de ese país" (comerciante de abarrotes, 37 años).

- "No, porque allá hay mucha perdición" (chofer de taxi, 50 años).

- "No le agrada Estados Unidos, nada de lo que se dice le llama la atención" (aluminero, negocio propio, 35 años).

- "No, porque las costumbres son muy diferentes. En México existe más libertad y oportunidad de trabajar" (exitoso en su negocio propio, 48 años). 
- "No, a mí me gusta mucho mi país" (licenciado en economía, fabricante de muebles, 48 años).

- "No me gusta ese país" (trailero, con experiencia en carreteras norteamericanas, 37 años).

- "No, porque allá es puro encierro, la gente no se mueve" (nativo de Eagle Pass, Texas; propietario de negocio de abarrotes, 69 años).

ii) Una cuarta parte de los jefes de hogar de la muestra de viviendas de Ciudad Guadalupe, N. L. carecían de experiencia laboral en Estados Unidos y manifestaron su deseo de trabajar en ese país. A este grupo se les dirigió la pregunta: ¿por qué no se ha decidido a trabajar en Estados Unidos? Las respuestas más frecuentes a esta pregunta fueron: "es muy dificil conseguir papeles"; "no lo he hecho por mi familia"; "no quiero dejar a la familia sola"; "ya se me pasó la edad para eso".

Desde otro ángulo, las respuestas de quienes desearían emigrar pueden distribuirse en función de la intencionalidad del entrevistado. En la mayoría de los casos, como se observa en el cuadro 1, los jefes de hogar que desearían trabajar en Estados Unidos no tienen intención de hacerlo. Es decir, tienen la plena conciencia de que una cosa es el deseo y otra la realidad: no van a obtener "papeles", no están dispuestos a emigrar sin documentos, o la familia no estará de acuerdo.

\section{CUADRO 1. Intencionalidad en relación con la migración internacional de los jefes de hogar de ciudad Guadalupe (porcentajes).}

\begin{tabular}{lr}
\hline Ha intentado emigrar alguna vez a EE.UU. & 7.2 \\
Va a intentar emigrar a EE.UU. & 4.5 \\
Desearía emigrar, pero no lo va a intentar & 12.5 \\
No corresponde* & 75.8 \\
Total & 100.0 \\
& \\
\hline FUENTE: Encuesta Migración internacional desde la zona metropolitana de Mon- \\
terrey. COLEF/AMEP. 1991. \\
* Incluye a los que alguna vez. han emigrado a EE.UU., a los no \\
emigrantes que no desean trabajar en EE.UU.y a los que no contestaron.
\end{tabular}

iii) El conjunto de respuestas aportadas muestra claramente que, a pesar de la poca distancia que separa a la ZMM del mercado norteamericano, a pesar de la complementariedad de mercados entre ambos países (Rouse, 1989), y del atractivo producido por las importantes diferencias salariales, 
los entrevistados operan una tajante separación entre esos dos mundos sociales: México y Estados Unidos. Separación que se expresa a través de imágenes del otro.

En primer término, Estados Unidos es imaginado como un mundo hermético y, en consecuencia, repelente. Es una sociedad que no recibe, que no da la bienvenida, que no asimila. Está disefiada solamente para sí misma; un mundo en el que no tienen cabida los extraños. Los mexicanos, en especial, se perciben como grupo particularmente desechado, repelido; no se aduce a la dinámica de "vecinos distantes", sino a la mecánica de la cerrazón: a los que van a trabajar a allá, solamente se les ofrece migajas.

No se trata simplemente de otro mundo, como podría ser Brasil, Italia o Japón. Sino de un mundo que no admite la inclusión, quizás la presencia, de otros mundos, menos del mexicano. Estados Unidos es un mundo ad hoc, pero para los norteamericanos.

Desde esta imagen separadora es impensable que el crecimiento econominico de la sociedad mexicana pueda, en algún momento, provenir del impulso estadounidense. La imagen funciona como bisturi: "si les va bien a ellos, no tiene por qué imos bien a nosotros". No hay contigüidad en los beneficios.

Estados Unidos es, en segundo término, un mundo incompatible con el "estilo de vida" mexicano. No solamente no admite el "estilo mexicano", sino que es inadmisible imaginar negociaciones simbolicas con ese mundo. "No deseo trabajar en Estados Unidos porque no me gusta el estilo de vida de alla" significa: las diferencias son de tal magnitud que no dan lugar a la negociación. No hay códigos comunes, puntos de amarre, zonas compartibles. La única negociación posible con ese mundo sería la abdicación, no sólo porque así lo exige ese mundo hermético, sino además porque se trata de dos mundos cuya composición es radicalmente diferente.

El verbo usualmente utilizado por los entrevistados para designar esta segunda imagen es precisamente el verbo gustar. No dicen: "no entiendo", "no conozco", "no acepto". Simplemente afirman: "no me gusta". Esto supone un ejercicio previo de degustación. Ya han probado, es decir, lo dan por conocido.

Estados Unidos por tanto no es percibido bajo la imagen de un mundo ignorado, lejano o exótico. Algunos mexicanos parecen darse por enterados y por tanto no quieren saber más. Lo que conocen no les gusta. Una afirmación muy primaria que remite a los sentidos. Es decir, a experiencias casi sensoriales, prerreflexivas, que permiten distinguir entre lo aceptable y lo inaceptable, lo gustable y lo insoportable.

En su conjunto, la negativa a trabajar en Estados Unidos no se sustenta en una reprobación de ese mundo. Salvo en algunas de las respuestas 
transcritas arriba, que incluyen evaluaciones de orden moral ("allá hay pura perdición"), los entrevistados aceptan que ese mundo tiene derecho a la existencia. No es un platillo insano, es simplemente un platillo que no corresponde a un sistema gustativo, el de los mexicanos.

Por último, una sección de las iespuestas da pie a pensar que en la mente de algunos entrevistados se percibe a Estados Unidos como un mundo especialmente antimexicano. Esta variante de la imagen difiere de las anteriores en términos de la intencionalidad que incluye. No se trata únicamente de hermetismo o incompatibilidad, sino de una imagen que señala una mala intención: la de usar a los mexicanos, la de robar, la de impedir el ejercicio de los derechos.

Estados Unidos es un mundo antimexicano, lo que significa que todo discurso generado desde allá, en tomo a México, es digno de sospecha. No hay lugar a buenas intenciones, a intercambio de pares, a buena vecindad. Hay lugar a la suspicacia: "algo se traen entre manos".

Valga añadir que no se imagina el mundo norteamericano como un mundo enemigo. La intencionalidad antimexicana hace nacer la sospecha, el diálogo taimado, la tensa relación, no la guerra. La imagen del enemigo supondría una declaración abierta, una concepción histórica de los procesos políticos y económicos. Estados Unidos no se define bajo la imagen del enemigo, ni del aliado. Estos no son los cuadrantes en operación. Sino bajo la imagen del vecino mal intencionado, indigno de confianza.

\section{COMPARACIÓN ENTRE LOS JEFES DE HOGAR QUE DESEAN $Y$ NO DESEAN TRABAJAR EN ESTADOS UNIDOS}

i) La muestra seleccionada incluye, por un lado, individuos adultos que no han trabajado en Estados Unidos y que desearían hacerlo, y por otro, individuos que no han trabajado en ese país y que no desean hacerlo. $\iota$ Existe una forma de caracterizar estos dos grupos? ¿Que diferencias hay entre ellos?

El imaginario sobre Estados Unidos y la posición del habitante urbano frente a la migración internacional no son autoproducidos. Se gestan en condiciones propias del individuo: edad, posición laboral, estrato socioeconómico, ${ }^{8}$ lugar de nacimiento.

La intención del presente apartado es discutir los resultados de ese análisis comparativo. Para ello, se utilizarán las variables anteriormente

8 Medido con base en la zona habitacional de residencia, se siguió una clasificación de zonas habitacionales en cuatro estratos sociocconómicos: marginal, bajo, medio y medio alto. Ciudad Guadalupe no posee zonas habitacionales consideradas de estrato alto. 
mencionadas y se discutirán sus efectos sobre la posición del entrevistado respecto a la migración internacional.

ii) La edad del entrevistado cumple una función muy importante. La edad promedio de los individuos que desearían trabajar en Estados Unidos es 40.6 años, mientras que la edad promedio de los que rechazan la idea de laborar fuera de México es 45.2 años.

El cuadro 2 permite apreciar más claramente el papel que juega esta variable. El deseo de trabajar en Estados Unidos crece notablemente en los jefes de hogar residentes urbanos menores de 35 años, disminuye claramente a partir de esa edad. De hecho, más del $40 \%$ de quienes desean trabajar en Estados Unidos son jóvenes (18 a 34 años).

Esto significa que la negativa a emigrar es en cierta medida una función de la edad. El discurso sobre el rechazo a la migración internacional es entonces, al menos parcialmente, una manifestación de estrategias laborales y de lógicas biográficas. Imaginarse trabajando en Estados Unidos es un acto admisible hasta cierta edad.

Esta dinámica de la edad sobre el deseo de trabajar en la Unión Americana debe, sin embargo, matizarse mediante el análisis de otras variables.

CUADRO 2. Deseo de trabajar en Estados Unidos según grupos de edad. Jefes de hogar de ciudad Guadalupe N.L. sin experiencia migratoria internacional (porcentajes).

\begin{tabular}{lcccl}
\hline $\begin{array}{l}\text { Año de } \\
\text { nacimiento }\end{array}$ & \multicolumn{5}{c}{ Deseo de trabajar en EE.UU. } \\
& Sí & No & Total & \\
\hline $1904-1937$ & 19.2 & 80.8 & 100 & $(73)$ \\
$1938-1948$ & 24.1 & 75.9 & 100 & $(108)$ \\
$1949-1956$ & 28.0 & 72.0 & 100 & $(100)$ \\
$1957-1973$ & 48.1 & 51.9 & 100 & $(108)$ \\
Todos & 30.8 & 69.2 & 100 & $(389)$ \\
\hline
\end{tabular}

FUENTE: Encuesta Migración internacional desde la zona metropolitana de Monterrey. COLEF/AMEP, 1991.

Chi-2=22.5 $\mathrm{P}=0.00005$

iii) Afirmar que se desearía trabajar en "el otro lado" también depende del estrato social del entrevistado. $37 \%$ de los individuos clasificados en los estratos marginal y bajo manifiestan este deseo contra solamente el $17 \%$ de quienes pertenecen a los estratos medios (bajo y alto). 
EL IMAGINARIO SOBRE LA MIGRACIÓN INTERNACIONAL

CUADRO 3. Deseo de trabajar en Estados Unidos según edad y estrato socioeconómico.* Jefes de hogar de ciudad Guadalupe N.L. Sin experiencia migratoria internacional (porcentajes).

\begin{tabular}{|c|c|c|c|c|c|c|}
\hline \multirow[t]{3}{*}{ Edad } & \multicolumn{6}{|c|}{ ESTRATOS SOCIOECONÓMICOS } \\
\hline & \multirow{2}{*}{\multicolumn{3}{|c|}{$\begin{array}{c}\text { Estratos bajos } \\
\text { Deseo de trabajar EE.UU. }\end{array}$}} & \multirow{2}{*}{\multicolumn{3}{|c|}{$\begin{array}{c}\text { Estratos medios } \\
\text { Deseo de trabajar EE.UU }\end{array}$}} \\
\hline & & & & & & $\begin{array}{c}\text { EE.UU. } \\
\text { Total }\end{array}$ \\
\hline 35 años y más & 30.5 & 69.5 & $\begin{array}{c}100 \\
(187)\end{array}$ & 11.7 & 88.3 & $\begin{array}{l}100 \\
(94)\end{array}$ \\
\hline 17 a 34 años & 52.5 & 47.5 & $\begin{array}{l}100 \\
(80)\end{array}$ & 35.7 & 64.3 & $\begin{array}{l}100 \\
(28)\end{array}$ \\
\hline
\end{tabular}

FUENTE: Encuesta Migración internacional desde la zona metropolitana de Monterrey. COLEF/AMEP. 1991.

* Por sectores residenciales.

CHI-2=11.64 $\mathrm{P}=0.0006 \quad \mathrm{CHI}-2=8.7 \quad \mathrm{P}=0.003$

La primera lectura del análisis muestra que ambas características funcionan en un mismo sentido: más de la mitad los jóvenes (17 a 34 años) de estratos bajos manifestaron su deseo de trabajar en Estados Unidos contra solamente el $11.7 \%$ de los adultos (35 y más años) de estratos medios. La negativa a imaginarse trabajando en un país extranjero es función de la edad y del estrato simultáneamente.

Sin embargo, como se observa en el cuadro 3 , la edad no produce efectos homogéneos en los dos estratos socioeconómicos considerados. En los individuos de estratos bajos, la edad es un diferenciador menos importante que en los miembros de estratos medios. Se reconoce que la edad reduce el efecto del estrato, aunque al interior de cada estrato el hecho de ser joven cumple una función importante. En otros términos, los jóvenes de ambos estratos tienen distribuciones similares en relación con su deseo de migrar a Estados Unidos.

Esta asociación entre la edad y el deseo de trabajar en Estados Unidos se observa más claramente en el cuadro 4 , en donde se introduce la variable "posición laboral". Ciertamente los individuos que trabajan en los sectores "informales" de la economía presentan un interés mayor por el mercado laboral norteamericano. Sin embargo, la influencia de la posición laboral sobre el deseo de migrar es notable solamente en el grupo de individuos con más de 34 años. En los jóvenes de diferentes posiciones laborales, las proporciones casi no varían: $56 \%$ de los que están trabajando en los 
CUADRO 4. Deseo de trabajar en Estados Unidos en función de la edad y la posición laboral. Jefes de hogar de Cd. Guadalupe N.L. sin experiencia migratoria internacional (porcentajes).

\begin{tabular}{|c|c|c|c|c|c|c|c|c|c|}
\hline \multirow[t]{3}{*}{ Edad } & \multicolumn{9}{|c|}{$\begin{array}{l}\text { Deseo de trabajar en EE.UU. } \\
\text { Posiciones Laborales }\end{array}$} \\
\hline & \multicolumn{3}{|c|}{ Bajo(*) } & \multicolumn{3}{|c|}{$\operatorname{Medio}(* *)$} & \multicolumn{3}{|c|}{$\operatorname{Alto}(* * *)$} \\
\hline & Sí & No & Total & Si & No & Total & Sí & No & Total \\
\hline 35 y más años & 32.4 & 67.6 & $\begin{array}{c}100 \\
(111)\end{array}$ & 21.1 & 78.9 & $\begin{array}{c}100 \\
(128)\end{array}$ & 12.28 & 7.8 & $\begin{array}{l}100 \\
(41)\end{array}$ \\
\hline 17 a 34 aก๊os & 56.7 & 43.3 & $\begin{array}{l}100 \\
(30)\end{array}$ & 44.8 & 55.2 & $\begin{array}{l}100 \\
(67)\end{array}$ & 45.5 & 54.5 & $\begin{array}{l}100 \\
(11)\end{array}$ \\
\hline
\end{tabular}

FUENTE: Encuesta Migración internacional desde la zona metropolitana de Monterrey. COLEF/AMEP 1991.

* Sectores agropecuario, informal, desempleados

** Asalariados

*** Profesionistas, propietarios

CHI-2=5.9 P=0.015 CHI-2=11.9 P=0.0005 CHI-2=6.2 P=0.013

sectores "informales" manifestaron interés por trabajar en Estados Unidos; lo mismo sucede con $44 \%$ de los asalariados y $45 \%$ de los profesionistas o propietarios.

Estos datos indican que persiste entre los habitantes urbanos jóvenes un malestar. Las oportunidades que ofrece el mercado de trabajo de la ZMM serían, para muchos de ellos, independientemente del estrato social y de su posición laboral, menos atractivas que las que les ofrecería el mercado norteamericano.

\section{CONCLUSIÓN}

Las dos secciones que forman el presente artículo permiten mostrar la existencia de lo que podemos llamar una tensión en el imaginario sobre la migración internacional dentro de la población urbana y adulta del sexo masculino.

\footnotetext{
9 La función discriminatoria de la variable edad es mucho mayor que la de otras: lugar de nacimiento, posición laboral y estrato socioeconómico. El valor del coeficiente estandarizado de la función discriminante para cada una de estas variables es: edad ( 0.851$)$, posición laboral $(0.425)$, estrato socioeconómico $(0.305)$, lugar de nacimiento $(0.076)$. La función construida con estas cuatro variables no permite predecir, sin embargo. más que a $62 \%$ de los casos de la muestra.
} 
Por un lado, es innegable que la sociedad y el mercado laboral de Estados Unidos es definido - imaginado- críticamente por numerosos entrevistados, quienes a su vez manifiestan que no desearían trabajar fuera de México. Sin embargo, esta visión está principalmente construida por individuos que sobrepasan los 35 afos.

Por otro lado, se observa que los jóvenes, inclusive los que presentan posiciones laborales estables y no pertenecen a estratos socioeconómicos desfavorecidos, no temen imaginarse a sí mismos como migrantes internacionales. Muchos de ellos no intentarán esta aventura laboral, pero se permiten este juego que engendra la pregunta: ¿Le gustaría trabajar en Estados Unidos?

La tensión observada entonces se localiza precisamente en las relaciones que establecen las expectativas, por un lado, y las percepciones, por el otro. El país vecino es definido como hermético, incompatible con el estilo de vida mexicano y, además, antimexicano. Pero también es percibido como una oportunidad para quienes, por su edad y condición social, podrían aprovechar el dinamismo de su economía. La visión crítica de la sociedad y el mercado norteamericano no impiden la consideración de que ahí se sitúan potencialmente mejores expectativas laborales para muchos jóvenes que las que les ofrece una ciudad como Monterrey.

\section{BIBLIOGRAFÍA}

BUSTAMANTE, Jorge A. 1990. Undocumented migration from Mexico to the U.S. En: Voices of Mexico. Mexican Perspectives on Contemporary Issues, CISEUA/UNAM, no. 20.

COATSWORTH, J.H. y Rico, C. 1989. "Introducción", Coatsworth, J.H. y Rico, C. (coordinadores) Imágenes de México en Estados Unidos, Fondo de Cultura Económica, México, D.F.

COLEF/AMEP. 1991. Migración internacional desde la zona metropolitana de Monterrey.

CONTEE, Christine E. 1989. "Percepciones estadounidenses sobre las relaciones entre México y Estados Unidos". Coatsworth, J.H. y Rico, C. (coordinadores) Imágenes de México en Estados Unidos, Fondo de Cultura Económica, México, D.F.

MORENO, Francisco J. 1992. "La imagen de los mexicoamericanos en los libros de texto de la educación elemental de San Diego, California". Historia y Cultura, Vol. VI, El Colegio de la Frontera Norte/Universidad Autónoma de Ciudad Juárez. 
POZAS, M. A. 1990. "El equipamiento urbano en Ciudad Guadalupe, $N$. L." Instituto Latinoamericano de Estudios Trasnacionales (reporte técnico, mimeo).

ROUSE, R.C. 1989. "Mexican Migration to the United States: Family Relations in the Development of a Transnational Migrant Circuit". $\mathrm{Ph}$. D. Dissertation, Stanford University.

VILLA, Pablo. 1992. "Visiones a través de la frontera El Paso-Ciudad Juárez: identidades sociales en la frontera México-americana". Ponencia presentada en el encuentro interno COLEF, Tijuana, B.C. 22-24 de octubre. ZÚÑIGA, Víctor. 1990. "Utilización de los espacios sociales en Cd. Guadalupe, N.L." Instituto Latinoamericano de Estudios Trasnacionales (reporte técnico, mimeo). 